Supplement of The Cryosphere, 15, 215-231, 2021 https://doi.org/10.5194/tc-15-215-2021-supplement C Author(s) 2021. This work is distributed under the Creative Commons Attribution 4.0 License.

(c) (1)

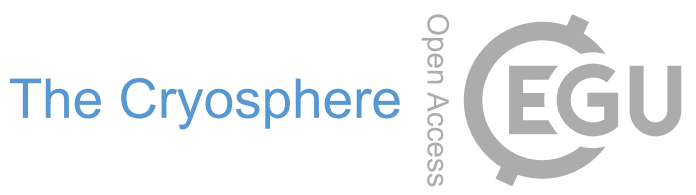

Supplement of

\title{
Exploring the impact of atmospheric forcing and basal drag on the Antarctic Ice Sheet under Last Glacial Maximum conditions
}

Javier Blasco et al.

Correspondence to: Javier Blasco (jablasco@ucm.es)

The copyright of individual parts of the supplement might differ from the CC BY 4.0 License. 

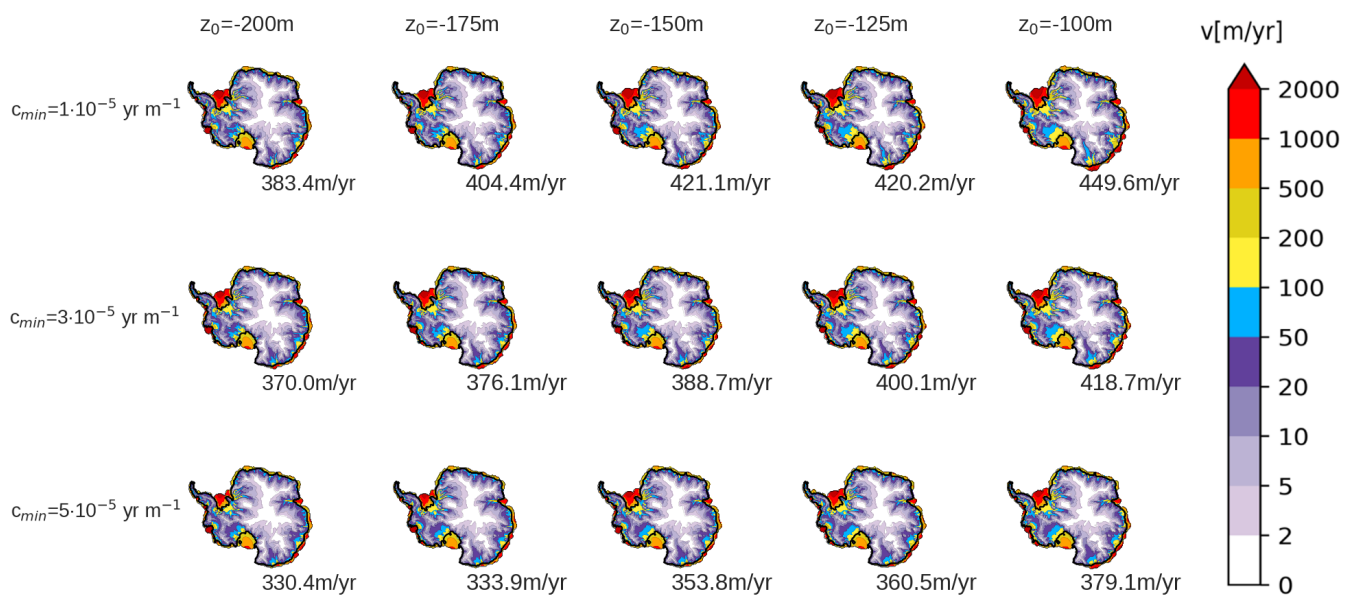

Figure S1. Simulated velocity pattern of the simulated PD state the employed friction parameters. Black line represents the actual grounding line position. The number in each panel shows the root mean square error (RMSE) of the surface ice velocity. 


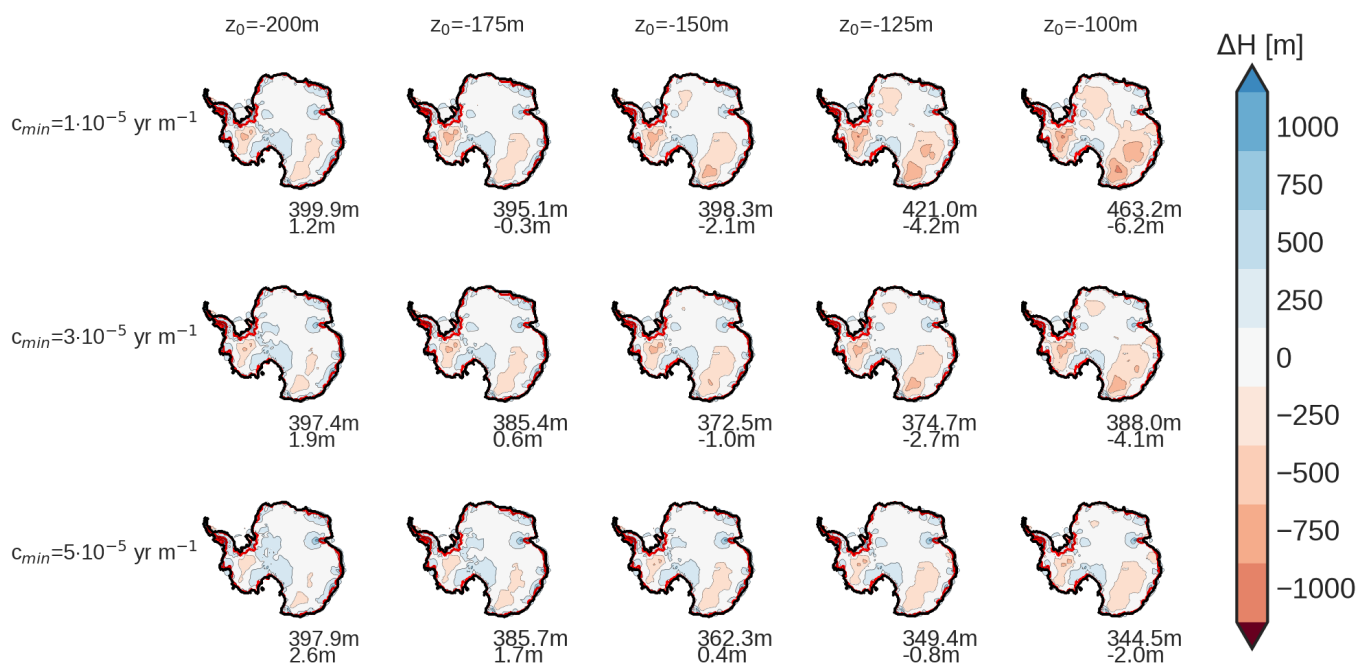

Figure S2. Ice thickness anomaly between the simulated and the observed by Schaffer et al., (2016) PD AIS states (simulated minus observed) for $c_{\max }=200 \cdot 10^{-5} \mathrm{yr} \mathrm{m}^{-1}$. The tick red line represents the actual grounding line position, black line the simulated grounding line position. The upper number in each panel shows the RMSE of the ice thickness for the corresponding set of parameters; the lower number represents the SLE anomaly with respect to PD. 


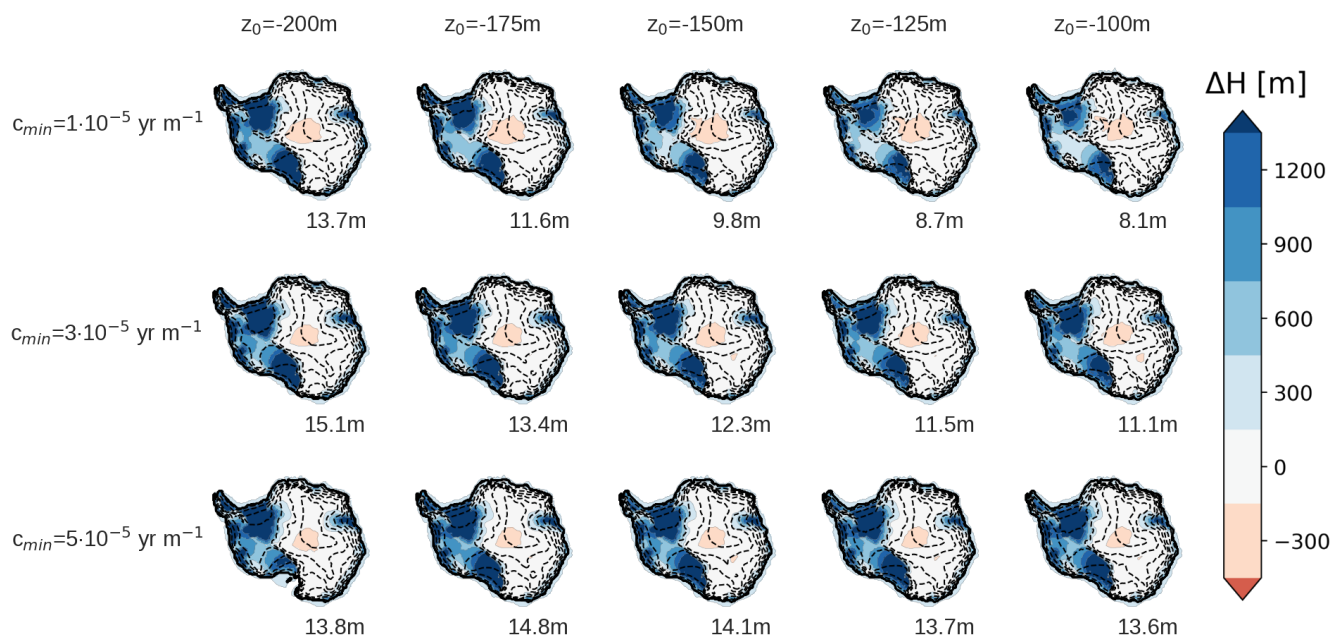

Figure S3. Ice thickness anomaly between the simulated LGM and PD AIS states (LGM minus PD) for all the ensemble members. Black line represents the grounding-line position. The black discontinuous contours show surface elevation every $500 \mathrm{~m}$ intervals up to $3500 \mathrm{~m}$ above sea level. The number in each panel shows the ice volume difference between the simulated LGM and PD state in terms of msle. 

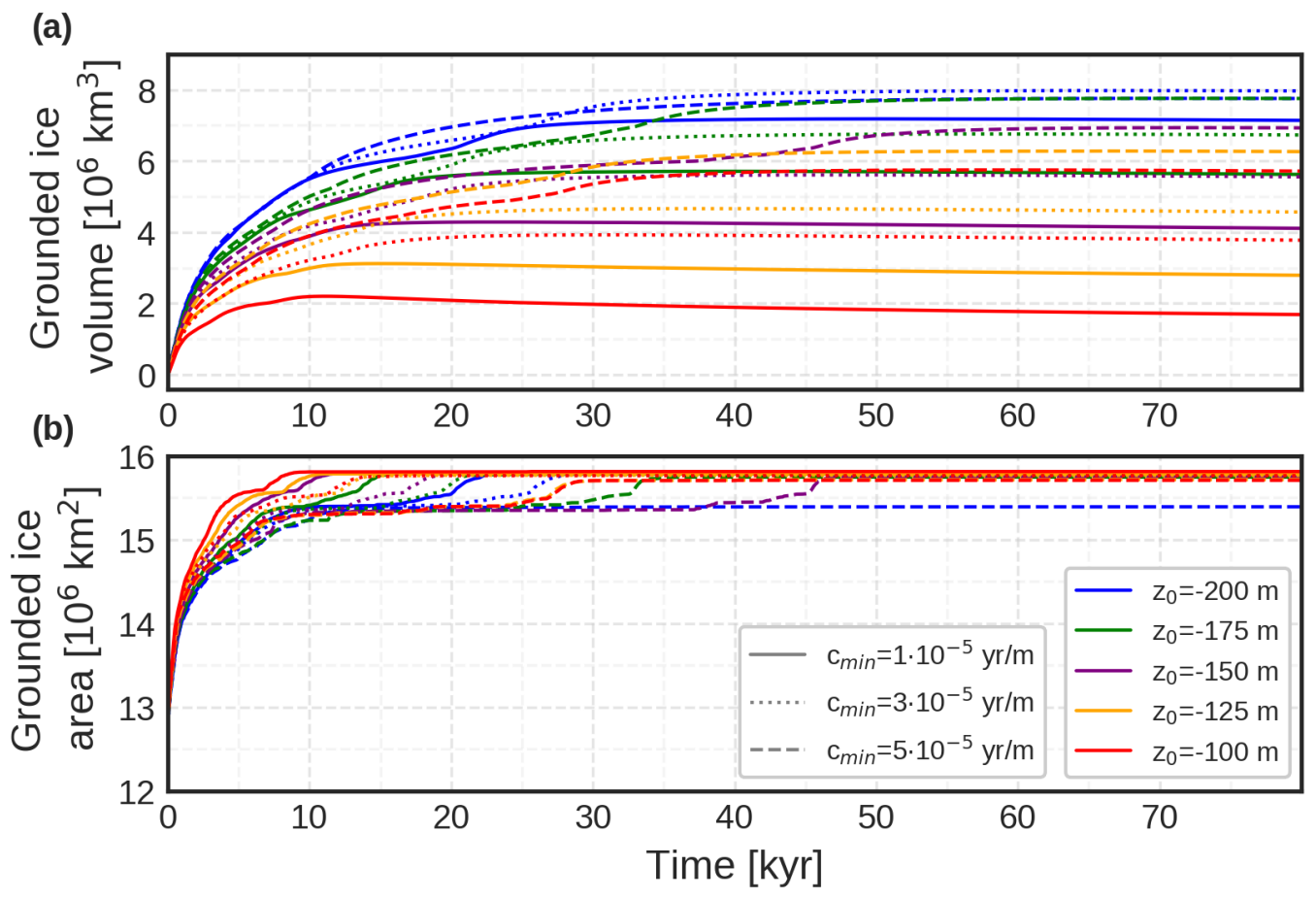

Figure S4. Simulated (a) ice volume and (b) ice extent time evolution for the friction parameters ensemble. 


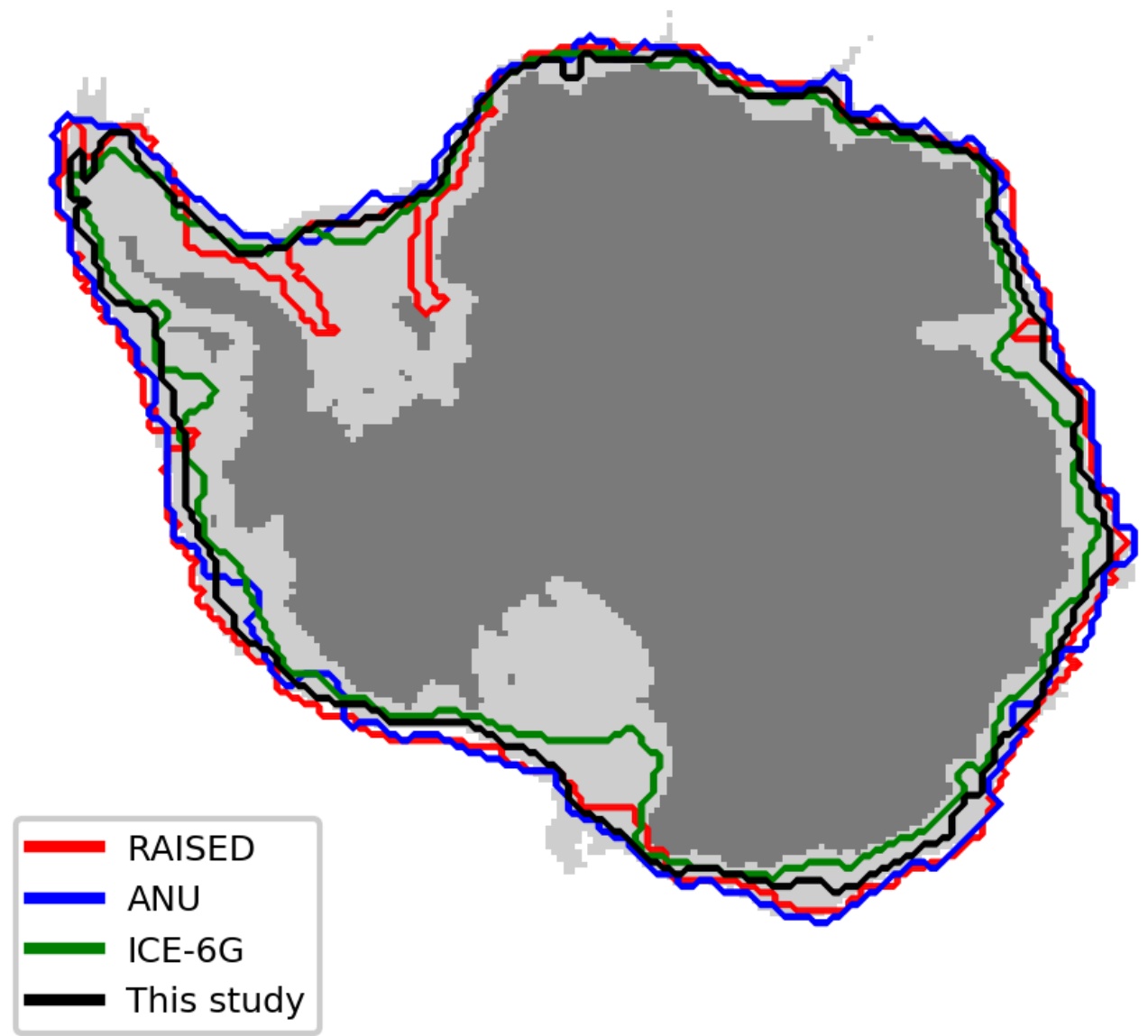

Figure S5. Grounded ice extensions reconstructions from RAISED Consortium in red; ANU in blue and ICE-6G in green. In black, the simulated ice extension in this study for $z_{0}=-125 \mathrm{~m}$ and $c_{\min }=5 \cdot 10^{-5} \mathrm{yr} \mathrm{m}^{-1}$. The grey dark area shows the PD grounded ice. The area between the PD grounded area and the continental-shelf break $\left(z_{b}<-2000 \mathrm{~m}\right)$ is shown in light grey. 


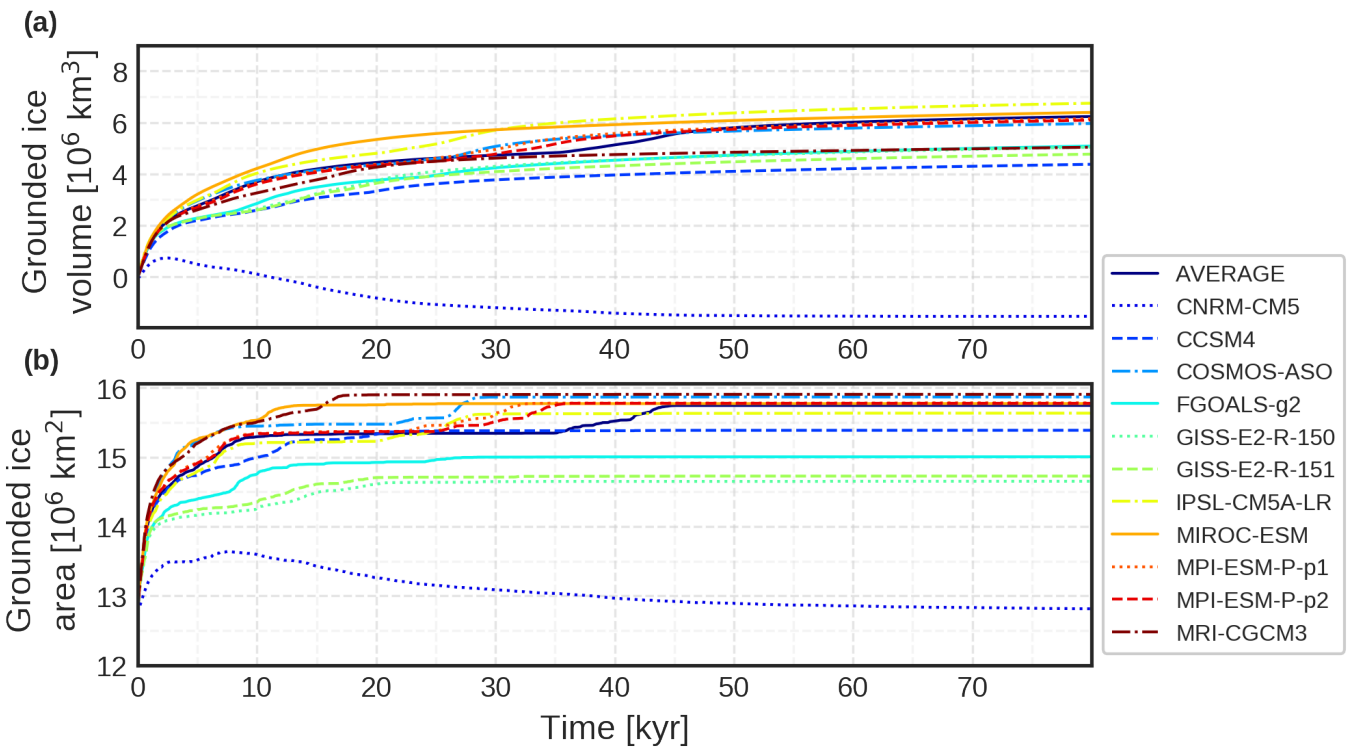

Figure S6. Simulated (a) ice volume and (b) ice extent time evolution for the whole PMIP3 ensemble and the reference friction parameters $z_{0}=-125 \mathrm{~m}$ and $c_{\min }=5 \cdot 10^{-5} \mathrm{yr} \mathrm{m}^{-1}$. 


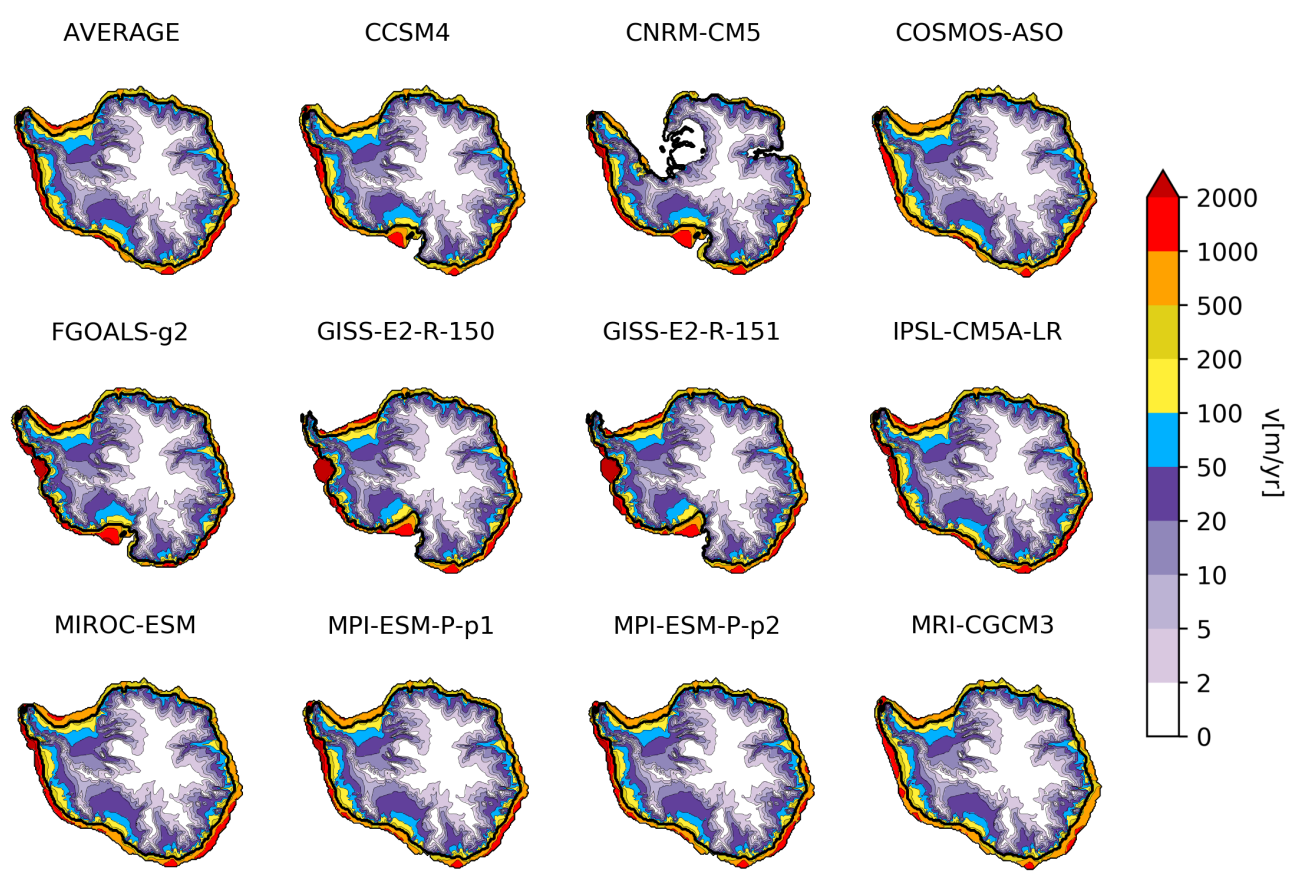

Figure S7. Snapshot of the horizontal integrated velocity for all the PMIP3 members. 

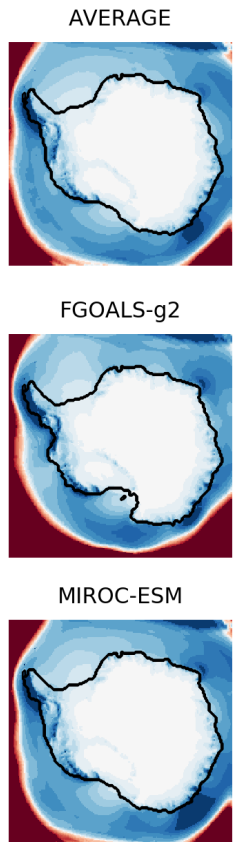

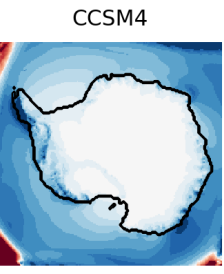

GISS-E2-R-150
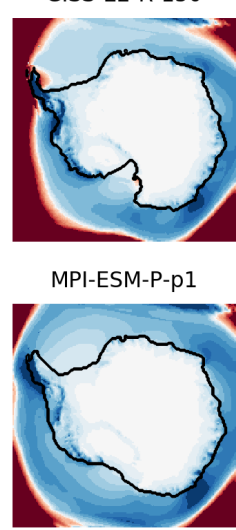

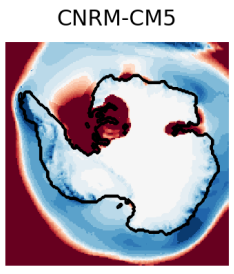

GISS-E2-R-151
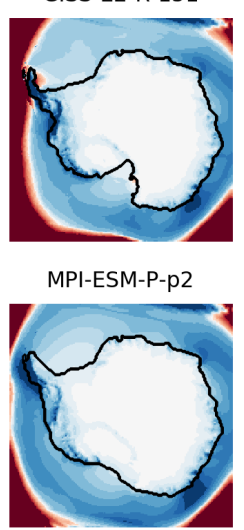

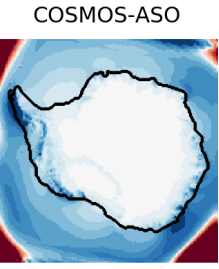

IPSL-CM5A-LR

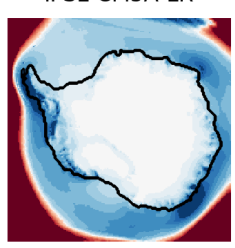

MRI-CGCM3

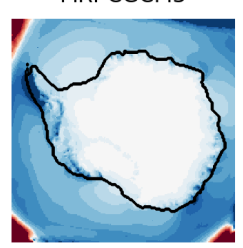

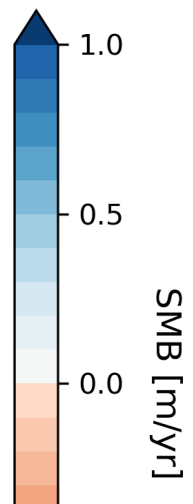

$-0.5$

Figure S8. Surface mass balance of all the AIS's simulated with Yelmo using the ensemble mean PMIP3 climatological anomalies and those of the individual model members. Negative numbers represent mass loss; positive numbers, mass gain. Black lines represent the simulated grounding-line extension. 

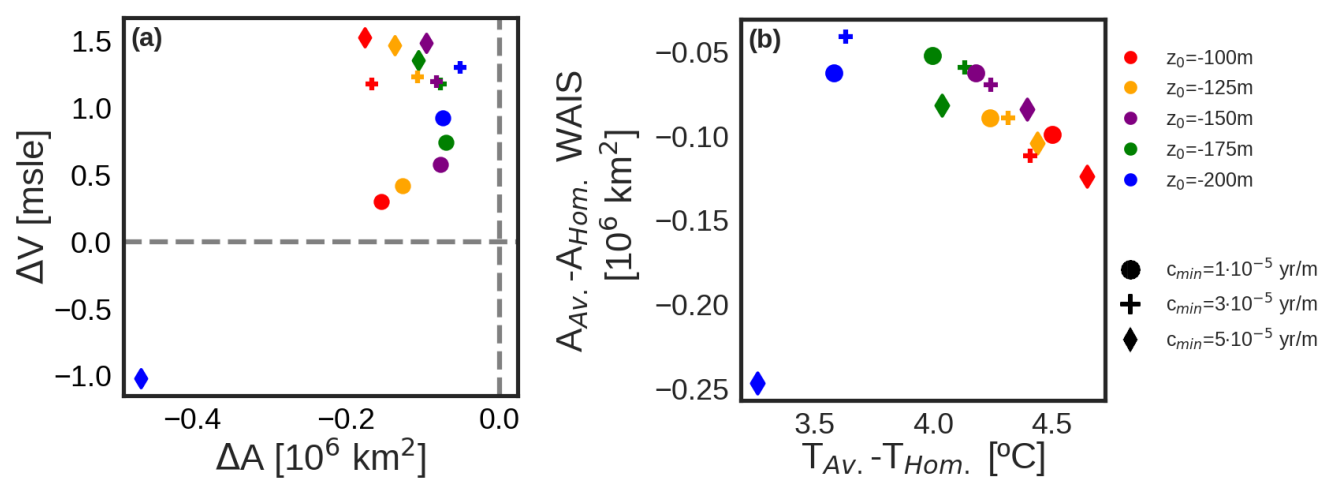

Figure S9. Difference in (a) grounded ice volume against grounded ice area; (b) grounded ice area against mean ice temperature at the grounding line between the PMIP3 ensemble mean and a spatially homogeneous anomaly (PMIP3 ensemble mean minus spatially homogeneous) for all permutations of basal friction parameters. 


\begin{tabular}{|l|l|l|l|l|}
\hline & V $32 \mathrm{~km}[\mathrm{msle}]$ & V $16 \mathrm{~km}[\mathrm{msle}]$ & A $32 \mathrm{~km}\left[10^{6} \mathrm{~km}^{2}\right]$ & A $16 \mathrm{~km}\left[10^{6} \mathrm{~km}^{2}\right]$ \\
\hline AVERAGE & 72.8 & 73.0 & 15.7 & 16.0 \\
\hline COSMOS-ASO & 72.2 & 72.3 & 15.9 & 16.1 \\
\hline PD & 58.7 & 57.6 & 12.9 & 13.0 \\
\hline
\end{tabular}

Table S1. Table summarizing the simulated ice volume (in msle) and grounded ice extension (in $10^{6} \mathrm{~km}^{2}$ ) for different resolutions. 

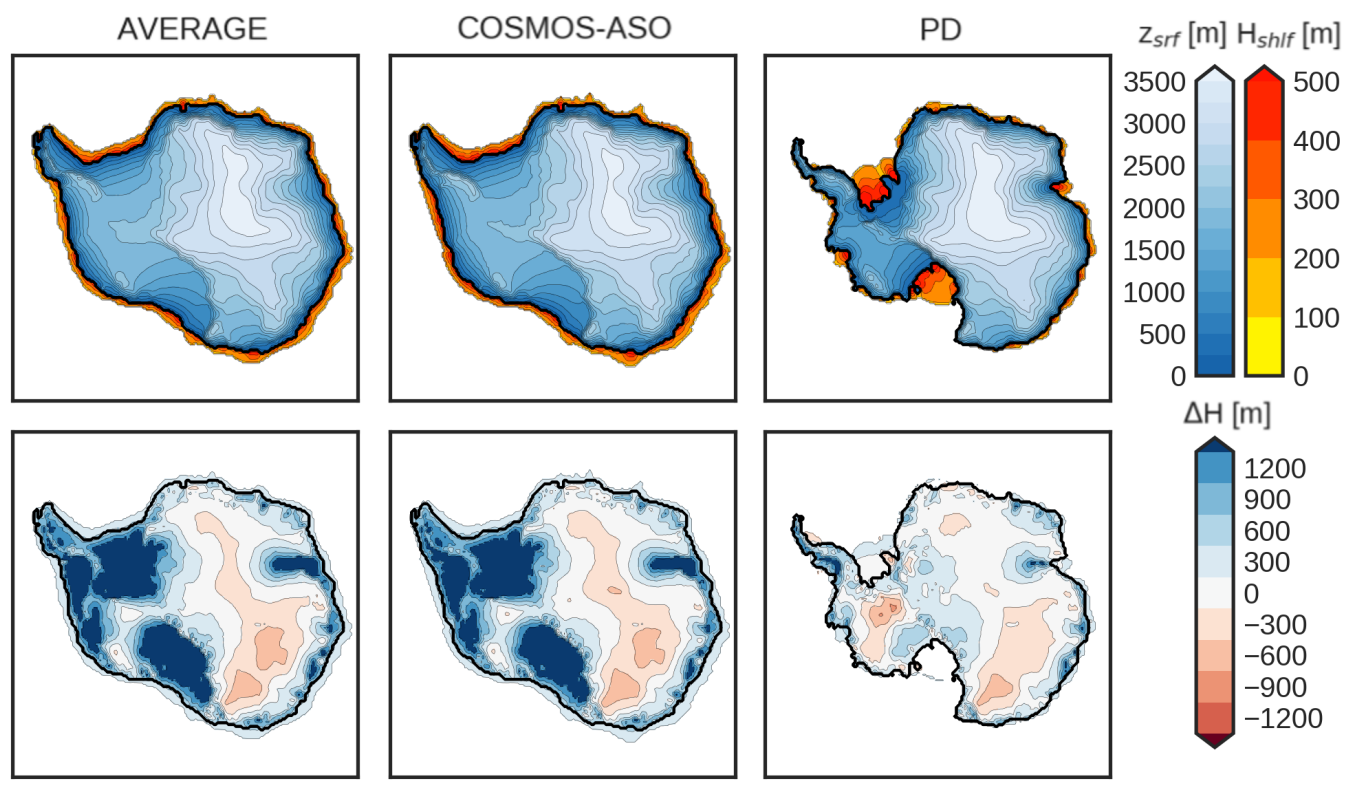

Figure S10. Upper row: Simulated surface elevation and ice shelf thickness for AVERAGE, COSMOS-ASO and PD at $32 \mathrm{~km}$ resolution. Lower row: ice thickness anomaly with respect to the simulated PD (LGM-PD). In the case of the PD the ice thickness anomaly is drawn with respect to observations (simulated PD - observed PD). 

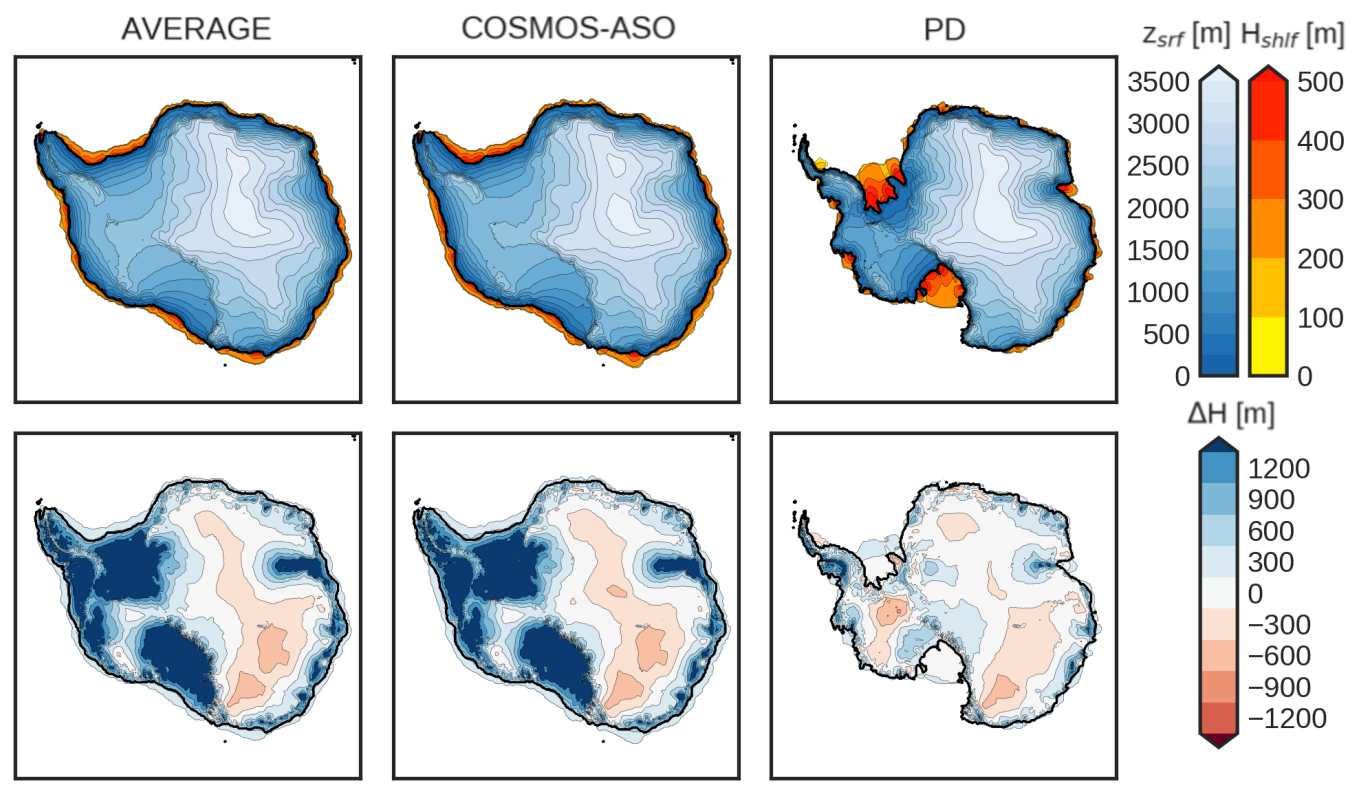

$\Delta H[\mathrm{~m}]$
1200
900
600
300
0
-300
-600
-900
-1200

Figure S11. As Figure S10 but for a horizontal resolution of $16 \mathrm{~km}$. 

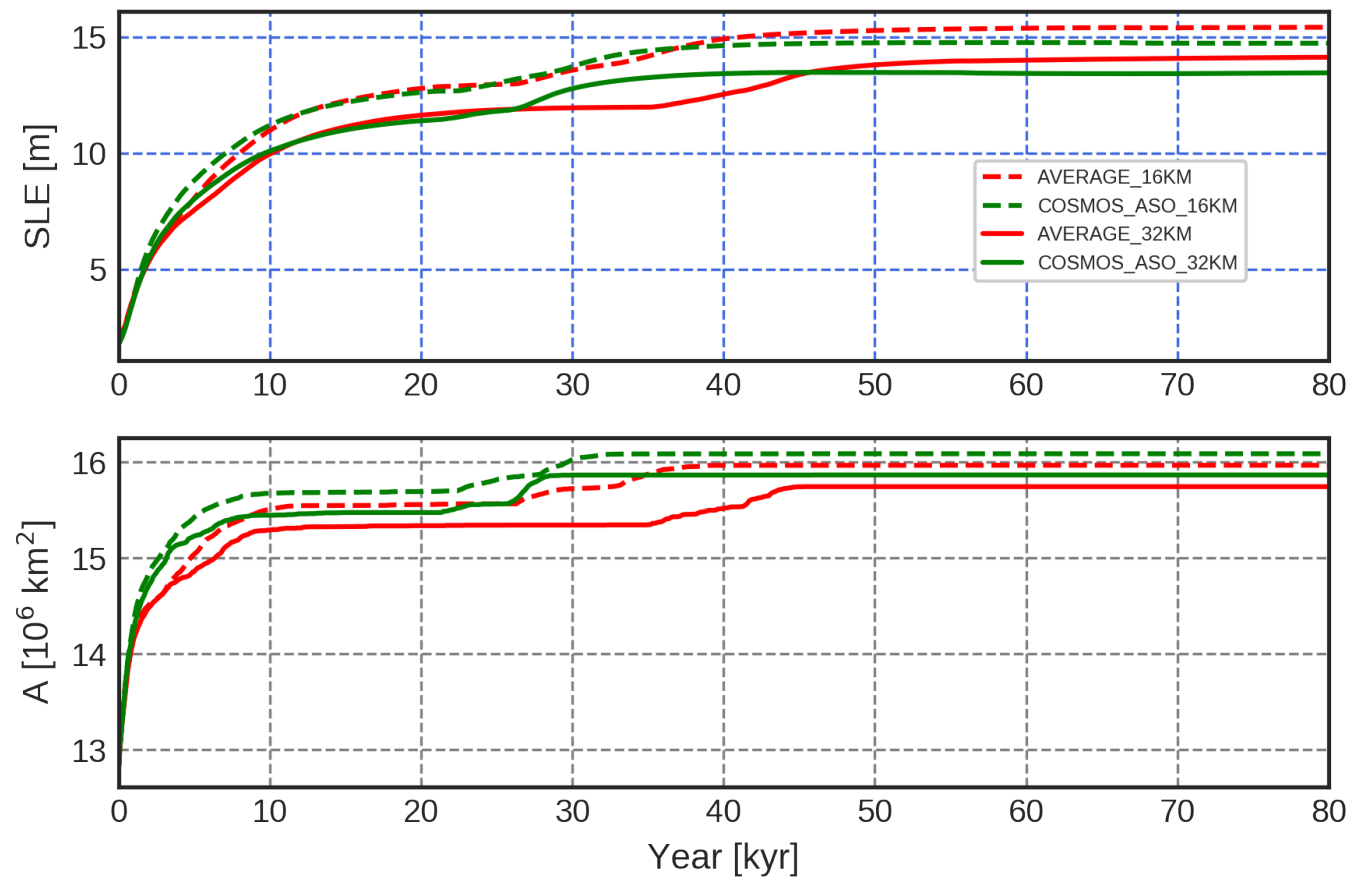

Figure S12. Ice volume evolution in terms of SLE and grounded ice area evolution for two PMIP3 members and the average with $32 \mathrm{~km}$ and $16 \mathrm{~km}$ resolution. 